\title{
The early semantics of the neologism BREXIT: a lexicogrammatical approach
}

Lise Fontaine(10

Correspondence: FontaineL@cf.ac.uk Cardiff University, Cardiff, UK

\begin{abstract}
The aim of this paper is to examine the nominality of the neologism BREXIT using a corpus-informed lexicogrammatical approach. The term BREXIT, coined in 2012, used initially in print and social media in the UK is now internationally wide-spread. BREXIT is a blend of British + exit, which expresses the meaning of'Britain exiting from the EU'. Although 'Brexit' clearly expresses an event (motion) meaning, as a nominalization, it also expresses nominal meaning. In systemic functional linguistics (SFL), nominalization is much broader than lexical derivation and is treated as a means of conceptualising and encoding experience. In this paper the development of BREXIT is explored using a corpus of 1,641,903 words including 2,435 instances of BREXIT from its first use in May 2012 to the UK general election in 2015. Capturing the development of this term from its initial use allows some insight into the intended meanings of the speaker due to the glosses provided. These appositional expressions are combined with the collocations found in the corpus. The results show that while the meanings identifiable in the corpus are entirely nominal in use, the term encodes complex meanings of eventoriented meanings and of hypotheticality. In examining the nominal status of BREXIT, I show that not all nominalizations are instances of grammatical metaphor.
\end{abstract}

Keywords: Nominalization, Word formation, Lexical semantics, Lexicogrammar, SFL, Grammatical metaphor

\section{Introduction}

It is well established in the literature that the semantics of a lexical item is understood, in part at least, by the association of the item to the other lexical items used around it. This position has been captured most famously by Firth's well cited claim that "you shall know a word by the company it keeps" (Firth 1957:11), but more recently shown in Hanks (2013). However new words are formed in the English language regularly and this means that, in theory, they are candidates for providing a non-historical perspective on their meaning in use. In other words, it is not possible to know what company a new word keeps. Any newly-formed word is formed for a purpose and therefore it is reasonable to assume that the word will bear some meaning that is related to its context of use.

This paper examines the neologism BREXIT from the period when it was first coined (2012) until the United Kingdom (UK) general election in May 2015. The Referendum held on June 232016 made Brexit a household word but consideration of more recent uses of Brexit have not been included this paper. While not yet appearing in most

(c) The Author(s). 2017 Open Access This article is distributed under the terms of the Creative Commons Attribution 4.0 International License (http://creativecommons.org/licenses/by/4.0/), which permits unrestricted use, distribution, and reproduction in any medium, provided you give appropriate credit to the original author(s) and the source, provide a link to the Creative Commons license, and indicate if changes were made. 
dictionaries, it does appear as an entry on Wikipedia and it was named the word of the year 2016 by Collins Dictionary. However, it has been used extensively in print and social media in the UK and in Europe. BREXIT is a blend of Britain or British with exit. Its formation was influenced by analogy to the term Grexit, which is also a relatively recently blend (Greek + exit), although older, and which was coined in response to the Greek debt crisis in 2010. Both Grexit and Brexit capture the meaning of 'an exit from the European Union'. This clearly expresses an event-oriented meaning but while exit can be seen as a nominalization, as will be discussed below, the lexeme BREXIT is not a nominalization in the strictest sense since it is formed by an adjective-noun blend rather than the more typical deverbal nominal transpositions (i.e. the nominal is formed without recourse to nonnominal meanings or items, cf. Mackenzie 2007). In systemic functional linguistics (SFL) nominalization is much broader than lexical derivation and is rather treated as a means of conceptualising and encoding our experience but the concept of nominality plays a central role in this (see Halliday, 1966 and Fontaine 2015, for example). In discussions of the membership of the United Kingdom in the European Union, we might ask whether media reports are reporting on this membership congruently, which in SFL terms means that things are represented by nouns and events are represented by verbs.

The aim of this paper is to examine the neologism BREXIT within its context of use and to determine its nominal meaning from the following three perspectives: the type of nominal meaning it expresses, i.e. whether it has object-oriented or event-oriented meaning; whether or not its realization is congruent, i.e. whether it is an instance of grammatical metaphor; and by considering its collocates in a corpus of its use in online news media. In order to do this, the formation and development of BREXIT section will first explain the origins of the lexeme and provide some basic background information about its context of use. Following this, the data and methods section will the nature of the corpus used and the approach taken in the analyis. In the Emerging patterns of use for BREXIT section I present the arguments surrounding the analysis of BREXIT as a nominal. This section is divided into three parts, each of which responds to the three aims of the paper. First I examine the type of nominal that BREXIT represents. Then the case for BREXIT as a nominalization is debated and while I conclude that in this case it is an instance of grammatical metaphor, the argumentation does raise some difficult questions for the theory. Finally, a corpus of 1,641,903 words is examined in order to summarise the lexicogrammatical patterns identified and whether BREXIT has developed any strong collocations in the period from its introduction in 2012 to the UK general election in May 2015. Finally, in the Conclusion section, the paper argues that while BREXIT should be treated as a complex nominal, it is not because it has been derived as a deverbal noun. Further, I show that it is not the case that all nominalizations are instances of grammatical metaphor and I argue that SFL must develop more robust criteria for making this distinction.

\section{The formation and development of BREXIT}

While BREXIT is too new to have appeared in dictionaries at the time of writing, it is very clear from its use that the lexeme was coined in May, 2012 (confirmed on Twitter and in Nexis ${ }^{\oplus}$, see Data and methods section below). See example (1) below for the earliest use of BREXIT that this author could find on Twitter, suggesting it was first used in a blog post. 
(1)British Influence @britinfluence 15 May 2012 Stumbling towards the Brexit - Britain, a referendum and an ever-closer reckoning: Nucleus News

In the corpus of texts collected for this study, there are instances of BRIXIT, showing some variation in the form of the blend but this instability did not last and BREXIT has now clearly been established as the only form of the lexeme. It is not clear whether the BR- in BREXIT is from Britain or British but it is more likely that it is the adjective form British, rather than the noun form Britain. The difference lies in whether exit is nominal or verbal, i.e. a British exit from the European Union or Britain exits the European Union. In some respects, the source of the BR- in BREXIT is not significant since either form identifies who or what is engaged in the exit and this is overtly marked. The covert relation then is the other anticipated entity involved in an exit; i.e. an exit involves a going out of somewhere, and in this case the somewhere is the European Union. It is reasonable then to consider that BREXIT has been formed from a blend of BR and EXIT (but cf earlier variation BRIXIT which seems now to have disappeared in favour of the now standard BREXIT). EXIT itself is a borrowing from Latin as a noun at some time prior to 1564 and according to the OED, it is borrowed as a noun of action from two formations (OXFORD ENGLISH DICTIONARY “exit, v. and n.” OED Online. Oxford University Press, September 2015): (1) < Latin exit, 3rd person singular indicative of Latin exire 'to go out', < ex'out' + ire 'to go' and (2) < Latin exitus (u- stem) 'going out, departure'. The English verb EXIT (meaning 'to depart') is formed in English by conversion from the noun (i.e. exit v. < exit n) (OXFORD ENGLISH DICTIONARY “exit, v. and n.” OED Online. Oxford University Press, September 2015) and is attested from 1607.

Conversion is a very productive and common word formation process. The process takes place without any overt morphological markings and consequently the word class is only identifiable when the word is seen in use and, for example, is inflected for plural as a noun or tense as a verb. Conversion is a particularly productive process in English. Barber (1997:238) explains that in the ME period, the most common type of conversion was denominal verbs, i.e. verbs derived from nouns. Given that the formation of EXIT in English takes place in the ME period, it is reasonable to assume that its conversion would have been supported by the same process happening to other nouns at the time.

The formation of BREXIT, however, was not due to conversion but rather to a blend, even though EXIT as part of the blend carries in it aspects of the verb conversion. As Plag (2003:155) explains, a blend "involves two or (rarely) more base words (instead of only one), but shares with truncations a massive loss of phonetic (or orthographic) material”. Examples of blends in English include brunch, blog and emoticon. In the case of BREXIT, the blend is formed from BRITAIN and EXIT and has the meaning of 'Britain exiting from the EU' or 'Britain's exit from the EU' or 'British exit from the EU'. Blends not only blend sounds but also meanings and behind them the conceptual meanings of the words blended together. According to Benczes (2006): 58), "[t]he language user needs to construct blends on the basis of conceptual metaphors and metonymies and pre-existing frames of understanding, which are then moulded in the blend to fit the discourse context". This is an important aspect of blends that we will return to below since it contributes to the semantic complexity of the term.

It is clear from the early examples of BREXIT in examples (2) to (6) below that the context of situation of the blend is the membership status of the United Kingdom, 
which is commonly referred to as Britain even if this is not politically or geographically accurate. The economic and political debate about Britain's membership in the European Union became increasingly uncertain leading up to May 2012 following the Greek economic crisis and the question about whether the UK would leave the European Union became topical in print and online news media as well as in blogs and on Twitter. In its early form while there was some variation in spelling (BRIXIT and BREXIT), it standardised quickly as BREXIT and in each case BREXIT is represented as functioning in a nominal way, i.e. as a noun (e.g. a Brexit).

(2) THERE'S a new word on the lips of Eurocrats at the moment: Brexit, short for British exit. (Express, 26 Oct 2012)

(3) Mr Cameron's much-trailed Europe speech, expected in mid-January, will seek to tread a delicate line, promising renegotiation to avoid a Brexit, or British exit from the EU. (The Telegraph, 28 Dec 2012)

(4) The European media had been filled for weeks with speculation about a Brexit, a British withdrawal from the European Union, partly pushed from Europe and partly pulled by the British. (UPI, 26 Nov 2012)

(5) The so-called Brexit question - the issue of whether Britain is heading for the EU exit door - has been a few years in gestation in Brussels (The Guardian, 27 Dec 2012)

(6) But a so-called "Brexit" does not seem to trouble some Europeans (AFP, 1 Dec 2013)

As new words are coined, they are generally marked in some way as they enter the language. Bauer (1983): 42) explains that:

When a word first appears in a language, whether as a loan or calque, or as a nonce formation, it appears that speakers are aware of its newness, that is they are aware that they are exploiting the productivity of the language system. Thus, in modern journalistic language the word is often put in inverted commas, a phrase is added such as "what has been called", "as it is termed" and so on, or a complete gloss is provided.

Clearly in the examples above, we find markers of this awareness. These have been highlighted in bold and we find a range of the features that Bauer lists as identifying evidence that the speakers (in these cases, writers) recognise that BREXIT is not an established lexeme. These features include an awareness of its newness, recognition that the productivity of the language system is being exploited, the use of 'so-called' and scare quotes, and explanations and definitions of the term in apposition or in a non-restrictive relative clause (cf. Goatly (1997, 171-175) typology of "definitional contexts"). However, neologisms such as this do not always survive and the lifespan or "currency" (Bauer 1983: 43) of a word is affected by many factors, which include, according to Bauer: the status of the person using the term, the attitude to the word evinced by society as a whole, whether or not there is a need for the form. At the time of writing this paper (2016), it is clear that BREXIT is fully established as a lexeme as we will see below.

\section{Data and methods}

The texts used in this study were gathered using Lexis Nexis Academic, an online database that contains full text newspaper articles from around the word in a variety of 
languages. The search term used was 'Brexit' resulting in a corpus of English language news including at least one mention of this term from 2012 to May 2015. The end date was selected to correspond with the UK election. Consequently, the corpus includes all instances of BREXIT from the time that the term was first coined to the UK election on May 5 2016. This is particularly significant since a Conservative Party election would mean that a referendum would be called on UK membership in the EU, which did indeed happen and a referendum was held in the UK on 23 June 2016. SketchEngine (Kilgarriff et al. 2014) was used to analyse the corpus in terms of concordances, collocations and word sketches and to extract examples from the corpus. The Brexit corpus size is 1,641,903 tokens and within this, the term 'Brexit' has a total frequency of 2,435 instances. While non-English examples were excluded from this corpus, it is clear from examples (7) to (9) that the term had gained some currency in German, Spanish and French language newspapers.

(7)Börsen-Zeitung Freitag 2. November 2012

Was niemand braucht, ist eine weitere Abkopplung Großbritanniens von der EU.

Nicht zufällig hat der Albtraum der EU-Spitzen mittlerweile mehrere Namen: Nicht bloß Grexit, sondern auch Brexit.

(8)El Pais October 26, 2012 Friday Primero fue Grexit, la combinación de Greece (Grecia) y exit (salida). Ahora es Brexit o Brixit para referirse a una posible salida de Reino Unido de la UE (British exit).

(9)La Tribune Lundi 22 Octobre 2012 C'est le nouveau néologisme à la mode dans les milieux financiers et politiques, "Brexit ». Une salade linguistique assez surprenante issue de "Grexit », lui-même désagréable mélange de " Greece » (Grèce) et « Exit » (sortie), cette fois agrémentée du B initial de "Britain », Grande-Bretagne. On tremble de voir arriver sur nos écrans et nos journaux les futurs «Spexit », "Itexit » ou, pire, "Frexit », avant le niveau ultime de la crainte universelle, " Gexit »...

What examples (2) through (9) illustrate is that, concerning the term 'Brexit', the context of situation is clearly based in economic and political discussions of the UK's membership and relationship to the European Union. Following the Conservative Party win in the 2015 general election in the UK, a referendum was called and as shown in example (10), it was referred to as 'the Brexit referendum'. The outcome of the referendum was a vote to leave the European Union and as a result 'Brexit' has become a very frequently heard term throughout the UK as suggested by example (11). In these two examples, the word is presented as an established term that does not require any explanation or indicators that it is new or unusual, as we will see in examples of its early uses.

(10) What the Olympics have shown is that for all the doom and gloom about Brexit, Britain retains extraordinary strengths. (DAILY MAIL (London) August 22, 2016)

(11) A Tim Shipman's new Brexit book has some juicy claims that David Cameron muttered to colleagues that May was 'lily-livered' (such an old-fashioned, yet utterly Cameroonian turn of phrase) on the issue. (Huffington Post, September 26, 2016) 


\section{Emerging patterns of use for BREXIT}

In this section, the nominal status of BREXIT is considered in terms of nominalization and grammatical metaphor. Following this, the analysis of the corpus is presented showing how, despite how relatively new the word is, it has established itself in certain patterns of use.

\section{The Nominality of BREXIT}

As was discussed in the formation and development of BREXIT section, BREXIT is a lexeme formed by a blend of 'British' and 'exit', which makes it a complex lexeme as it carries a phrasal meaning, i.e. Classifier + Thing in experiential terms or modifier + head in logical terms (see Fontaine 2017b), and so it is effectively a condensed noun phrase. It came into use as a noun which is clear in examples (1) and (4) in particular. As mentioned above, the etymology of 'exit' shows that it was borrowed from Latin to English as a noun, although it carries an event meaning rather than a thing meaning. While it is possible to create event nouns through derivation-based nominalizations, some nouns carry an inherent event meaning, despite not having been derived from a verb. As Vendler (1967:141) explains:

There are certain nouns that are not verb derivatives, yet behave like nominalised verbs; that is, they can enter container contexts without suggesting suppressed nominals. Fires and blizzards, unlike tables, crystals, or cows, can occur, begin, and end, can be sudden or prolonged, can be watched and observed - they are, in a word, events and not objects.

In other words, since an exit (at least in the sense evoked in Brexit) can be sudden or prolonged and it can be observed (e.g. 'I watched his abrupt exit'), it is an event rather than an object. However, its behaviour in the grammar is clearly nominal. The verb form exit, as explained above, derives from the noun form by conversion (or zero derivation). There is a distinction to be made between event nouns that derive from nominalised verbs, e.g. refusal < refuse v. + -al suffix ("refusal" n.) and event nouns that are not, e.g. fire ("fire", n. and int.). The lexeme exit is somewhat ambiguous in this distinction since it was, in its parent language, Latin, derived from a verb. In SFL, nominality is not limited to morphological nominalization but is rather a broader term that captures what happens when anything is 'objectified', including entire clauses, events, and attributes (Fontaine 2015). As Halliday, Michael (1966:69) explains, "once something is nominal or is made nominal, it inherits "the potentialities otherwise reserved to persons and objects".

What this statement implies is that there are different types of nominals. One type includes those that are reserved to persons and objects and by this we can presume nouns like chair and tree and possibly also less concrete nouns such as sky and nominalizations such as appliance and teacher. However, there are other types that are not reserved to persons and objects and have an event-type meaning such as fire and exit as mentioned above but also storm, meeting, circus and transformation. The challenge with these nouns is that it is very difficult to tell just by looking at them whether they encode event meaning or object meaning. There is an object meaning to 'exit' (e.g. where's the exit?). We can distinguish the object and event nouns by using the criteria that were suggested above and we would 
conclude that in the object meaning, an exit cannot be observed over time or be prolonged, although it can be seen and touched. We could add to this the fact that it can be counted (for example on an airplane, the airline attendants will identify the location of the various exits that can be found on the plane). Further, an exit can be destroyed or painted like a box or a door. Therefore, it may be the case that we need to distinguish event nominals from object nominals either in terms of homonymy (different lexemes) or polysemy. In SFL there is a tendency to prefer homonymy over polysemy and we may wish to refer rather to $\operatorname{EXIT}_{1}$ and $\operatorname{EXIT}_{2}$ where 1 has an object sense and 2 has an event sense (although see Hanks 2013 and many other scholars who would prioritise polysemy over homonymy for such closely-related words both semantically and etymologically).

Indeed, as Grimm and McNally (2013) have argued, a single nominal lexeme such as examination may in fact have the potential for three different noun types. The three types of nominal identified by Grimm and McNally (2013:124) for examination include complex event nominal, simple event nominal and result nominal, which they illustrate with the examples reproduced here in (12), where (12a), (12b), and (12c) illustrate each type respectively. The main distinction between (12a) and (12b) is whether the noun has an argument structure or not and the difference between (12c) and the other two examples relates to the fact that it is a non-event nominal (i.e. result, cf. 'exam') which denotes an actual concrete object. In more SFL terms, while (12a) may be seen as effectively a verb in a noun form (see the discussion of grammatical metaphor below), the same cannot be said for (12c) since it could be expressed as He gave the teacher his exam, where it is clear that the noun denotes a concrete object.

(12) a. The examination of the patients took a long time. (Complex Event nominal)

b. The examination took a long time. (Simple Event Nominal)

c. The examination was on the table. (Result Nominal)

What these examples show is that even with the same noun form, there is some ambiguity surrounding the nature of the representation. If we use these three types of nominal to develop criteria for testing nominal types, we could then determine the nature of exit as a nominal. As suggested above, while there is a clear basis for the lexeme having an event meaning at the point of entering the language, it remains to be established whether it has maintained an argument structure or not. In the BNC, nominal groups which follow 'the exit of' tend to refer to a location or a building that has an exit, e.g. 'the exit of the car park', where it is clear that the car park has an exit and it is not the case that the car park is exiting anywhere. However, although infrequent, we also find some evidence for exit as a complex nominal with argument structure, e.g. 'to permit ready exit of passengers in the event of an emergency'.

The point being made here is that not all nominalizations involve the same degree of complexity and also not all the devices for deriving nominals involve the same degree of complexity. However, what does seem to be apparent is that English has developed a very productive means of converting nouns into verbs and vice versa (see Fontaine, Lise 2017a). Halliday (2007: 363) sees this fluidity between nouns and verbs as an instance of complementarity, a particular type of indeterminacy where we can "[interpret] what 
goes on either as a construction of objects or as a flow of events". As suggested above, when an object-type realization is selected for an event-type of meaning, this is seen as an incongruent realization in SFL terms and this is one type of relation that is included as a type of grammatical metaphor. We will now consider the relationship between nominalizations and grammatical metaphor.

\section{Nominalizations and Grammatical Metaphor}

Grammatical metaphor, according to Halliday \& Matthiessen (2014: 730-731), occurs when "some aspect of the structural configuration of the clause, whether in its ideational function or in its interpersonal function or in both, is in some way different from that which would be arrived at by the shortest route - it is not, or was not originally, the most straightforward coding of the meanings selected". So far we have been discussing the relationship between object and event meanings in terms of nouns and verbs within a view of nominality. An incongruent realization of event meaning by a nominal form is indeed included as a type of grammatical metaphor, where more specifically "processes (congruently worded as verbs) and properties (congruently worded as adjectives) are reworded metaphorically as nouns; instead of functioning in the clause, as Process or Attribute, they function as Thing in the nominal group" (Halliday \& Matthiessen, 2014: 729). However, it should be clear at this point that not all nominalizations can be seen as grammatical metaphor, if we accept that nouns such as appliance, teacher, and storm, are congruently realized. Both appliance and teacher are derived from verbs but do not carry event meaning and storm, in contrast, while not derived from a verb, does carry event meaning since a storm is something that happens. It can be observed and it has a duration. One might want to argue then that storm is an instance of grammatical metaphor. As we consider whether a given expression is or is not an instance of grammatical metaphor, it is important to establish what the criteria are for determining this. The concept of congruence is central as is the identifiability of agnate or congruent realizations (cf. Heyvaert 2003). Therefore, in considering the nominal status of the neologism BREXIT we can ask two questions: Is the mapping between the semantics and the grammar congruent? Is there an agnate realization that identifies the event meaning?

The answer to these questions is more complex than it might at first seem. While there is an event meaning in BREXIT, which comes from the stem exit, it also, through the blend of 'Britain/British', encodes the agentive meaning in relation to the event, i.e. the noun encodes the complex meaning of 'Britain exiting (the EU)'. This is clear in the corpus under study in this paper through examples such as (13) given below.

\section{(13) a so-called "Brexit" or British exit from the EU}

It is clear from this example that the meaning of BREXIT encodes both the meaning of exiting as an event and the agentive meaning of who/what will be doing the exiting, even if the reference to Britain is to some extent metonymic. The entire nominal group given in (13) also includes, as a qualifier, an expression of motion, from the $E U$, which encodes a directional meaning (cf. Langacker, Ronald 1987:174). The lexeme BREXIT in use then encodes meanings that coerce or at least reinforce an incongruent realization in Halliday's sense of the term. Since the term evokes the event meaning 
and it is clear who the agent of exit is, it becomes easier to see that BREXIT is a nominal form that encodes a clause-like meaning, i.e. 'Britain exited from the EU', or more accurately, 'The United Kingdom exited from the EU'.

However, it is the very nature of the clause, through the transitivity system, to configure participants. Consequently, if we want to say something about an event, we need to have a mechanism by which it can be nominalized, otherwise the resulting restrictions would be too great. For example, if someone did something, e.g. someone donated money to a charity, and if this situation could then not be nominalized (be made nominal), then I would not be able to talk about the event or the situation itself. In other words, an event or situation needs to be available (i.e. have the potential) as a nominal in order to enter into a participant configuration. Hence, it is not only normal to create a nominal, it is essential to how we exchange information in English. Following this line of thinking, we may want to question the notion of congruence as it is currently applied in discussions of grammatical metaphor (see also Steiner 2004 and Hita and Jorge 2003). An event or situation once conceptualised is effectively nominal. With the example just given about someone donating money, it might be the case that someone says, 'My friend donated a lot of money to a cancer charity. That was a really nice thing to do.', where 'that' is clearly an anaphoric reference to the entire preceding clause. This type of nominalization, if we accept that it is a kind of nominalizing, may well be entirely congruent, although it seems clear that it involves a greater degree of complexity.

Discussions of nominality and nominalization do not necessarily imply nominal complexity or grammatical metaphor nor do they imply grammatical metaphor. As Halliday (2004b): 39) makes clear, "it would be wrong to equate grammatical metaphor with nominalization" and this is precisely what shows clearly in the data. However, there is nevertheless a close relationship between the two. For example, some nominalizations are viewed by Halliday as dead metaphors, e.g. "resistance in heat resistance" (Halliday 2004b:39) and ignorance (my example), where the metaphoric meaning "can no longer be unpacked" (Halliday 2004b:39). Underlying grammatical metaphor then is a kind of semantic shift and concerning nominal meanings, it involves "the way the grammar shifts from a predominantly clausal to a predominantly nominal mode of construal" (Halliday, Michael 2004a:191). In SFL this shift is generally viewed in terms of realization and congruence. As Taverniers, Miriam (2002: 10-11) explains, grammatical metaphor "is based on an 'alternative realization' of a meaning which can also be expressed congruently".

The concept of congruence is central to any discussion of grammatical metaphor as noted above. Halliday and Matthiessen (1999:235) describe the relationship between literal and metaphorical meanings as being along a continuum rather than as dichotomy. Their position is that " $[\mathrm{t}]$ he immediate evidence for this [grammatical metaphor] is historical" (ibid.) along three axes of (historical) development: the language itself (phylogenesis), the individual's language (ontogenesis) and the text (logogenesis). Studying the development of the neologism BREXIT shows that tracing meaning along these three axes is not a simple matter. Words do not enter the language in a vacuum, they come as part of a semantic network, often with complex associations as is the case here. If we were to apply these three axes to the use of BREXIT, we would find different results than what has been presented here since in many cases, the term appears first logogenetically and arguably (but this is debatable) also ontogenetically. The issue of its 
historical place phylogenetically will depend entirely on the assumptions on which the discussion is based. The semantic flexibility of the base item exit, allows for either the object-oriented or event-oriented meanings to be profiled. How then can we determine what is congruent? Steiner (2004: 146) articulates the problem very clearly, "whether some variant is 'direct' or 'indirect' (i.e. congruent or metaphorical) will have to be decided on the basis of the language specific 'histories' of the constructions in terms of phylogenesis (language history), ontogenesis (language development in the individual) and logogenesis (development of meaning(s) in (a) text(s)), and the answers are far from clear for our examples here". The complexities surrounding these issues are beyond the scope of this paper but it is clear that it merits further consideration.

\section{The nominal behaviour of BREXIT}

The final perspective taken on BREXIT in this paper involves an analysis of instances in a corpus of news media which dates from its first mention in 2012 to the UK elections in May 2015 as explained above in data and methods section.

The top collocates for BREXIT in the corpus overall are given below in Table 1 (below), where the collocates list is presented in logDice order, which is a statistic used in the SketchEngine platform to measure the strength of the collocation of two words where the corpus size does not affect the calculation (see Rychlý 2008). In this sense it can be a better metric than either T-score or MI score but both are presented here alongside the logDice for reference. The collocates listed in Table 1 is evidence of the awareness of the novel status of BREXIT (e.g. so-called, use of scare quotes and also the collocates British and exit). We also find markers of indefiniteness (indefinite article 'a') and modality ('would,' could,' 'possible,' potential'). Examples of these collocates are given below in (14) to (18).

Table 1 Frequency of collocations for BREXIT in the Brexit corpus

\begin{tabular}{lllll}
\hline & Frequency & T-score & MI & logDice \\
\hline So-called & 132 & 11.462 & 8.741 & 10.676 \\
Exit & 177 & 13.155 & 6.481 & 10.587 \\
' & 343 & 18.111 & 5.501 & 10.542 \\
British & 186 & 13.308 & 5.369 & 10.122 \\
Would & 310 & 17.007 & 4.877 & 10.055 \\
$"$ & 669 & 24.794 & 4.594 & 10.020 \\
a & 970 & 29.721 & 4.451 & 9.941 \\
Or & 143 & 11.549 & 4.871 & 9.675 \\
Prize & 60 & 7.732 & 9.095 & 9.614 \\
From & 190 & 13.103 & 4.338 & 9.472 \\
Referendum & 10.325 & 4.750 & 9.469 \\
- & 115 & 13.195 & 4.316 & 9.462 \\
Could & 193 & 10.127 & 4.688 & 9.412 \\
Risk & 111 & 7.935 & 5.987 & 9.412 \\
Possible & 65 & 7.647 & 6.285 & 9.378 \\
Potential & 60 & 7.396 & 6.417 & 9.317 \\
\hline & 56 & & &
\end{tabular}


(14) could result in economic losses/the break-up of the UK

(15) could cost Britain/David Cameron

(16) could affect the economy/plans/people

(17) a possible Brexit

(18) a potential Brexit

Perhaps a more surprising collocate is the lexical item prize but this is explained by the Brexit Prize which was announced by the Institute of Economic Affairs in 2013. This prize was being offered to the competitor who wrote the best "Blueprint for Britain outside the EU". Following the announcement of the competition and the submission deadline in February 2014, the winner was announced in April 2014. This prize received considerable media attention. Two examples of this collocation are given in (19) and (20) below.

(19) The Brexit prize, was organised by British right-wing think tank the Institute of Economic Affairs, and presented by former finance minister and veteran eurosceptic Nigel Lawson

(20) This winning entry of the IEA Brexit Prize * called for the UK to negotiate membership of the EFTA, though remaining outside the EEA

While the results presented in Table 1 cover the entire corpus, it is worth comparing the collocates found in two periods within the corpus. The first year (2012 to 2013) constitutes the very earliest uses of BREXIT as a term and as discussed above, there was some initial irregularity to its spelling and use and speakers marked their use of the term as a novel term. This is quite different to the period prior to the UK election in May 2015 since the term was no longer novel and it had become an issue in the election campaign. This is largely due to the commitment in the Conservative Party manifesto to hold an in/out referendum on the UK's membership in the European Union. In Table 2 below, the collocates of BREXIT are presented separately for the 2012-2013 period and for the 2015 period (January to May) respectively.

It is clear in Table 2 that even though this initial period covers eight months (recall that BREXIT was coined in May 2012), the size of this sub-corpus is considerably smaller than in the final period covering January to May, 2015. The 2012-2013 subcorpus contained 371 instances of BREXIT whereas in the 2015 sub-corpus this frequency rose to 1,326 . The rate of increase in the three-year period was exponential; the total frequency in the corpus as a whole is 2,435 which means that $54.5 \%$ of all instances are found in the last four months of the 36 month corpus.

Table 2 Collocates of BREXIT in 2012-13

\begin{tabular}{llllr}
\hline & Frequency & T-score & Ml & logDice \\
\hline Prize & 30 & 5.474 & 10.809 & 11.109 \\
So-called & 28 & 5.283 & 9.219 & 10.630 \\
Prize & 20 & 4.464 & 9.033 & 10.245 \\
IEA & 12 & 3.458 & 9.157 & 9.727 \\
Exit & 37 & 6.033 & 6.937 & 9.472 \\
\hline
\end{tabular}


In the 2015 sub-corpus there remains some evidence that the term is seen as novel or at least not entirely standard due to the collocation with so-called and with the use of scare quotes remaining at the top of the collocates list. What seems to be developing in the evolution of the term in news media is the association with various types of modality. We note a move from "so-called Brexit" and "Brexit Prize" in 2012-2013 to "potential Brexit negotiation/referendum/scenario" in 2015. Given the dominating theme of the referendum in the months leading up to the May 2015 election in the UK, it is not surprising to see referendum appearing as a significant collocate of BREXIT. Although not very frequent, we can see that there is evidence of comparison with the situation in Greece, whose financial crisis led to considerable doubts about its membership in the EU. Although not included here, it would be reasonable to expect different collocates in the period following the 2016 referendum, which would reflect a different context of situation. The degree of the resulting semantic shift, if any, remains to be determined.

An analysis of collocates only presents part of the picture. What is needed now is to gain a broader perspective on its use and look at a slightly larger co-text in order to better understand the meanings associated to BREXIT. Given its nature as a nominalization, this is perhaps even more significant. As Banks (2008: 130) explains,

[I]t is evident that the use of nominalisation is rooted in the situation. The nature of the activity going on to some extent determines the form of the language used. Thus the inseparability of the language from its situation is again in evidence.

It is important to keep in mind that implicitly encoded in the term BREXIT is a hypothetical meaning. This is not derived from the blend itself but from the context of situation and how it came to be coined. We find some evidence of this in the collocations listed in Table 3, where BREXIT collocates strongly with possible, would and potential.

Hanks (2013) concepts of norms and exploitations may be useful here. While a norm can be thought of as a typical phraseological pattern associated with a lexeme, Hanks defines an exploitation as a "deliberate departure from an established pattern of normal word use, either in order to talk about new or unusual things or in order to say old things in a new, interesting or unusual way" (2013: 212). When the term BREXIT was coined, it may be reasonable to say that the conceptual meaning required to capture the meaning of Britain leaving the UK drew on exploitations of the event-oriented lexeme EXIT. As discussed above, blends are constructed on the basis of "conceptual metaphors and metonymies and pre-existing frames of understanding, which are then

Table 3 Collocations of BREXT January to May 2015

\begin{tabular}{llrlr}
\hline & Frequency & T-score & Ml & logDice \\
\hline So-called & 72 & 8.465 & 8.744 & 10.587 \\
Exit & 197 & 13.742 & 5.578 & 9.971 \\
Possible & 72 & 8.358 & 6.060 & 9.792 \\
Would & 43 & 6.494 & 6.681 & 9.577 \\
Grexit & 184 & 13.141 & 5.001 & 9.480 \\
Referendum & 31 & 5.548 & 8.173 & 9.443 \\
Potential & 89 & 9.187 & 5.257 & 9.437 \\
\hline
\end{tabular}


moulded in the blend to fit the discourse context" (Benczes 2006: 58). This constructed blend is a type of exploitation in Hanks' sense. As he explains (2013: 211), "exploitation also has a diachronic dimension as a source of secondary norms: it accounts for the origin of new senses and the relationship between the literal meaning of a word and rhetorical or imaginative uses, some of which have themselves become established as secondary conventions". What is key for me in this perspective on BREXIT is that the new sense that has evolved from the initial exploitation has been nominal in the ways that we have shown here but that its nominality also encodes complex meanings of event-oriented meanings and of hypotheticality. What remains to be seen is what will happen to it as the UK moves past the June 2016 EU referendum. It cannot remain an exploitation since exploitations are temporary (Hanks 2013); it must either establish itself as a norm (or possibly a secondary norm) or fade into history. While the referendum itself became certain with the 2015 election, BREXIT, for now, remains a hypothetical construct since at the time of writing, it has not happened.

\section{Conclusion}

This paper set out to examine the nominal nature of the relatively recent neologism, BREXIT. Unlike many of the lexical items coined on a regular basis in the English language, BREXIT has not simply come into use in an ad hoc and temporary way (i.e. not fully adopted into the language). It has, on the contrary, gained media currency and is, at the time of writing, a term that all UK residents know. Its development in the threeyear period studied here has been shown to be fundamentally nominal by its behaviour; this lexical item is a member of the class of nouns and behaves as such. As a lexical item formed through blending, we find that its roots are in the adjective British and the noun exit. There is no evidence that it has developed as a deverbal nominal (other than historically and morphologically in Latin) and yet, BREXIT has incorporated the features of a complex nominal, including the potential for argument structure, inherited from the event meaning of exit, which as already stated, forms the base of the blend. It is perhaps because exit is fully maintained (orthographically and phonologically) that it carries this meaning so strongly. In this sense, it is not a typical example of a blend since it has not lost any part of its form, at least not the 'exit' part, and yet it is not a full compound either. Therefore, its nominal status is best seen as a complex nominal.

The paper has also shown that, in SFL terms, complex nominals are a type of nominalization that are candidates grammatical metaphor. There must be evidence for this determination and concerning BREXIT, it is clear from the corpus that it is a nominal form which is being used to express an event-oriented meaning. In other words, the process meaning of exit has been, according to Halliday, reworded metaphorically as a noun rather than congruently as a verb. This is often made explicitly clear in the corpus under study since, because of its novel use, and as shown above, speakers paraphrase this meaning with expressions such as 'short for British exit,' Britain's exit from the European Union' or 'Britain leaving the EU', all of which are expressions which cooccur with BREXIT in apposition. However, I have shown that not all instances of nominalizations can be described as grammatical metaphor. This is a challenging area for SFL because the relationship between the two is not always clear. We must develop criteria for making this distinction. These might include etymological or derivational 
information and whether there is sufficient evidence of metaphorical 'rewording' but it should involve lexicogrammatical evidence. Furthermore, as suggested above, we cannot simply assume that the relationship necessarily involves congruence. Future work needs to take on these important issues in a critically engaged way.

Finally, a corpus of news articles including the term BREXIT was analysed in order to describe its lexical meaning. By considering its collocates, we can clearly see that the meanings it carries from these patterns reflect the context in which it developed. These meanings include its novelty as a newly-coined word. As it increased in use over time, more interpersonal meanings emerge in association with BREXIT, encoding a kind of hypotheticality in its meaning. There is some evidence that its use had not fully normalised by May 2015, given the increase in collocation of so-called and the use of scare quotes. Indeed in a 2015 article in the Economist, BREXIT is marked as a novel expression and it is clarified in its event meaning in apposition to the noun, as shown in (21) below. It seems to have remained to some extent an exploitation and it has not been fully incorporated into what we might consider a full normative lexeme in English.

(21) SIX months ago the chances of "Brexit"- Britain departing from the European Union-seemed remote. Today, largely because of Europe's migration crisis and the interminable euro mess, the polls have narrowed. Some recent surveys even find a majority of Britons wanting to leave. [The Economist, Oct 19th 2015]

While the work presented in this paper covers only the first three years of use, there are good indications that BREXIT is still undergoing development. We will need a much larger corpus to build a better picture of its full meaning as a potential participant in the transitivity system, and in future work we would want to ask how it is represented in a configuration of participants. It will be interesting to compare its development from the 2015 UK election to the 2016 UK referendum on EU membership with its development post-referendum, given the outcome was in favour of leaving the EU. If the UK does exit the EU, perhaps the term will be restricted to history books. At the time of writing, 'Brexit' is on the tip of everyone's tongue in Europe.

\section{Abbreviations \\ SFL: Systemic functional linguistics}

\section{Acknowledgements}

An early version of this paper was presented at Change and Diachrony in Language and Text: A conference in honour of David Banks, Université Paris Diderot, Friday November 6th 2015. I am grateful for questions and comments from delegates at the conference.

Funding

No funding was provided to collect the data or to complete the research.

Availability of data and materials

Data used in this paper was obtained from publicly available newspaper articles which were access via the LexisNexis Academic website: http://www.lexisnexis.com/hottopics/Inacademic/. Accessed 7 December 2016. The texts included will not be shared due to the Terms \& Conditions of use for the LexisNexis Services.

Authors' contributions

The author contributed $100 \%$ of the content of this article. 
Received: 16 December 2016 Accepted: 6 February 2017

Published online: 02 March 2017

\section{References}

Banks, David. 2008. The Development of Scientific Writing, Linguistic Features and Historical Context. London: Equinox. Barber, Charles. 1997. Early Modern English, Newth ed. Edinburgh: Edinburgh University Press.

Bauer, Laurie. 1983. English Word-Formation. Cambridge: Cambridge University Press.

Benczes, Réka. 2006. Creative compounding in English: The semantics of metaphorical and metonymical noun-noun combinations. Amsterdam and Philadelphia: John Benjamins.

Firth, John Rupert. 1957. Papers in Linguistics 1934-1951. London: Oxford University Press.

Fontaine, Lise. 2015. The Noun, Grammar and Context. Keynote speaker, The Symposium on The Making of Meaning: Grammar, Society and Consciousness, in honour of Professor M.A.K. Halliday and Professor Ruqaiya Hasan. Beijing, China: Beijing Normal University.

Fontaine, Lise. 2017a. Fluid boundaries and the categorization of nominal expressions. In Stella Neumann, Rebekah Wegener, Jennifer Fest, Paula Niemietz and Nicole Hützen (eds) Challenging Boundaries in Linguistics: Systemic Functional Perspectives. Aachen British and American Studies Series. Frankfurt am Main: Peter Lang Verlag. DOl: http://dx.doi.org/10.3726/b10693

Fontaine, Lise. 2017b. The English Nominal Group: the centrality of the Thing element. In Tom Bartlett and Gerard O'Grady (eds) Routledge Systemic Functional Linguistic Handbook. London, Routledge, 267-283.

Goatly, Andrew. 1997. The Language of Metaphors: Literal Metaphorical. New York: Taylor \& Francis.

Grimm, Scott, and Louise McNally. 2013. No ordered arguments needed for nouns. In Proceedings of the 19th Amsterdam Colloquium, ed. Maria Aloni, Michael Franke, and Floris Roelofsen, 123-130. Amsterdam: ILLC.

Halliday, Michael. 2004a. On the Grammar of Scientific English. In Jonathan Webster (ed) The Language of Science (Volume 5 in the Collected Works of M. A. K. Halliday), 181-198. London: Continuum.

Halliday, Michael 2004b. Language and Knowledge: the 'Unpacking' of Text. In The Language of Science, ed. Jonathan Webster, (Volume 5 in the Collected Works of M. A. K. Halliday), 24-48. London: Continuum.

Halliday, Michael. 2007. On the concept of educational linguistics. In Language and Education (Volume 9 in the Collected Works of M.A.K. Halliday), ed. Jonathan Webster, 354-367. London: Continuum.

Halliday, Michael, and Christian Matthiessen. 1999. Construing Experience through Language: a language-based approach to cognition. London: Cassell.

Halliday, Michael, and Christian Mattthiessen. 2014. Halliday's Introduction to Functional Grammar. London: Routledge.

Halliday, Michael. 1966/2003. Grammar, society, and the noun. Reprinted in Michael Halliday and Jonathan. Webster. On Language and Linguistics. Collected Works of MAK Halliday, Vol. 3, 50-73. London: Continuum.

Hanks, Patrick. 2013. Lexical Analysis, Norms and Exploitations. Cambridge, USA: MIT.

Heyvaert, Liesbet. 2003. A cognitive-functional approach to nominalization in English (Cognitive Linguistics Research 26). Berlin: Mouton.

Hita, Jorge Arús. 2003. Ambiguity in grammatical metaphor: One more reason why the distinction transitive/ergative pays off. In Grammatical Metaphor, ed. Anne-Marie Simon-Vandenbergen, Miriam Taverniers, and Louise Ravelli, 101-126. Amsterdam and Philadelphia: John Benjamins.

Kilgarriff, Adam, Vit Baisa, Jan Bušta, Miloš Jakubiček, Vojtěch Kovář, Jan. Michelfeit, Pavel Rychlý, Vít Suchomel. 2014 The Sketch Engine: ten years on. Lexicography, 1, 1, pp 7-36. http://www.sketchengine.co.uk. Accessed 7 December 2016.

Langacker, Ronald. 1987. Foundations of Cognitive Grammar, Volume 1, Theoretical Prerequisites. Stanford: Stanford University Press.

Mackenzie, Lachlan. 2007. In Functional Perspectives on Grammar and Discourse: Papers in honour of Angela Downing, ed. Butler Christopher, Downing Raquel Hidalgo, and Lavid Julia, 217-232. Amsterdam: Benjamins.

OXFORD ENGLISH DICTIONARY "exit, v. and n." OED Online. Oxford University Press, September 2015. Web. 2 November 2015.

Plag, Ingo. 2003. Word-formation in English. Cambridge: Cambridge University Press.

Rychlý, Pavel. 2008. A lexicographer-friendly association score, 6-9. RASLAN: Proceedings of Recent Advances in Slavonic Natural Language Processing.

Steiner, Erich. 2004. Ideational grammatical metaphor: Exploring some implications for the overall model. Languages in Contrast 4(1): 137-164

Taverniers, Miriam. 2002. Systemic-Functional Linguistics and the Notion of Grammatical Metaphor: A theoretical study and a proposal for a semiotic-functional integrative model. Doctoral dissertation. Ghent, Belgium: University of Ghent.

Vendler, Zeno. 1967. Linguistics in Philosophy. Ithaca, NY: Cornell University Press.

Submit your manuscript to a SpringerOpen ${ }^{\circ}$ journal and benefit from:

- Convenient online submission

- Rigorous peer review

- Immediate publication on acceptance

- Open access: articles freely available online

- High visibility within the field

- Retaining the copyright to your article

Submit your next manuscript at $\boldsymbol{\nabla}$ springeropen.com 